\title{
From wind ensembles to probabilistic information about future wind power production - results from an actual application
}

Nielsen, Henrik Aalborg; Nielsen, Torben Skov; Madsen, Henrik; Giebel, Gregor; Badger, Jake; Landberg, Lars; Sattler, Kai; Voulund, Lars; Tøfting, John

\section{Published in:}

Prooceedings of the 9th International Conference on Probabilistic Methods Applied to Power Systems

Link to article, DOI:

10.1109/PMAPS.2006.360289

Publication date:

2006

Document Version

Publisher's PDF, also known as Version of record

Link back to DTU Orbit

Citation $(A P A)$ :

Nielsen, H. A., Nielsen, T. S., Madsen, H., Giebel, G., Badger, J., Landberg, L., Sattler, K., Voulund, L., \& Tøfting, J. (2006). From wind ensembles to probabilistic information about future wind power production - results from an actual application. In Prooceedings of the 9th International Conference on Probabilistic Methods Applied to Power Systems (pp. 1-8). IEEE. https://doi.org/10.1109/PMAPS.2006.360289

\section{General rights}

Copyright and moral rights for the publications made accessible in the public portal are retained by the authors and/or other copyright owners and it is a condition of accessing publications that users recognise and abide by the legal requirements associated with these rights.

- Users may download and print one copy of any publication from the public portal for the purpose of private study or research.

- You may not further distribute the material or use it for any profit-making activity or commercial gain

- You may freely distribute the URL identifying the publication in the public portal 


\title{
From wind ensembles to probabilistic information about future wind power production - results from an actual application
}

\author{
(Invited Paper) \\ Henrik Aalborg Nielsen*, Torben Skov Nielsen*, Henrik Madsen*, Gregor Giebel ${ }^{\dagger}$, \\ Jake Badger ${ }^{\dagger}$, Lars Landberg ${ }^{\dagger}$, Kai Sattler ${ }^{\ddagger}$, Lars Voulund ${ }^{\S}$, John Tofting I \\ *Technical University of Denmark, Informatics and Mathematical Modelling, DK-2800 Kgs. Lyngby, Denmark \\ ${ }^{\dagger}$ Risø National Laboratory, Wind Energy Department, DK-4000 Roskilde, Denmark

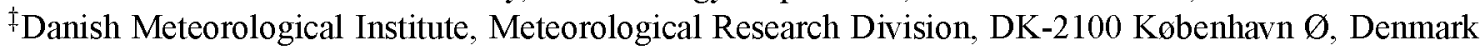 \\ ${ }^{\S}$ Energi E2 A/S, DK-2450 København SV, Denmark \\ IElsam Kraft A/S, DK-7000 Fredericia, Denmark
}

\begin{abstract}
Meteorological ensemble forecasts aim at quantifying the uncertainty of the future development of the weather by supplying several possible scenarios of this development. Here we address the use of such scenarios in probabilistic forecasting of wind power production.

Specifically, for each forecast horizon we aim at supplying quantiles of the wind power production conditional on the information available at the time at which the forecast is generated. This involves (i) transformation of meteorological ensemble forecasts into wind power ensemble forecasts and (ii) calculation of quantiles based on the wind power ensemble forecasts. Given measurements of power production, representing a region or a single wind farm, we have developed methods applicable for these two steps. While (ii) should in principle be a simple task we found that the probabilistic information contained in the wind power ensembles from (i) can not be used directly and therefore both (i) and (ii) requires statistical modelling.

Based on these findings an demo-application, supplying quantile forecasts for operational horizons of up to approximately 6 days, was developed for two utilities participating in a common project. The application use ECMWF-ensembles. One setup corresponds to an offshore wind farm (Nysted, Denmark) and one corresponds to regional forecasting (Western Denmark). In the paper we analyze the results obtained from 8 months of actual operation of this system.

It is concluded that the demo-application produce reliable forecasts. The average difference between the $75 \%$ and $25 \%$ quantile forecasts exceeds $\mathbf{5 0} \%$ of the installed capacity for horizons longer than approximately 4 days for the wind farm setup. For the regional forecasts the corresponding horizon is not reached within 7 days, which is the maximum horizon available. The ability of the demo-application to differentiate between situations with low and high uncertainty is analysed. Also, the relation between the forecasted uncertainty and the actual skill of a point forecast is analysed. A satisfactory agreement is observed.
\end{abstract}

\section{INTRODUCTION}

As part of the Danish PSO project Ensemble-forecasts for wind power (FU2101) [1] models for producing quantile forecasts of wind power production were developed. Based on this development a demo-application producing quantile forecasts of wind power has been developed. The models rely on meteorological ensemble forecasts as input. While traditional meteorological forecasts supply one scenario for the future development of the weather, ensemble forecasts supply several scenarios. These scenarios are often considered equally likely.

Here we consider ensemble forecasts of wind speed and direction $10 \mathrm{~m}$ above ground level from both ECMWF (European Centre for Medium-Range Weather Forecasts) and NCEP (National Centers for Environmental Prediction in the U.S.). These models are global models and the scenarios are basically generated by perturbing the initial conditions of the differential equations describing the global weather system [2]-[7].

Figure 1 shows an example of a quantile forecast of the wind power production in a region. To produce this forecast two models has been used. First a model describing the relation between unperturbed forecasts of wind conditions and the power production is used to produce a wind power ensemble forecast and secondly a model is used for transforming this power ensemble forecast into a wind power quantile forecast. While the latter may seem a trivial task our analysis show that the wind power ensemble forecasts are far from being probabilistic correct, which in turn must be rectified by a somewhat complicated model. In this paper the two models will be described and the results of a 8 months trial period of the demo-application will be summarized. More information can be found in [7]-[9].

The demo-application is used at the production companies Energi E2 A/S and Elsam Kraft A/S, both located in Denmark. At E2 it is used to forecast the production at the Nysted offshore wind farm with an installed capacity of $166 \mathrm{MW}$. At Elsam it is used to forecast the production of all wind farms in Jylland and Fynen (Western Denmark), excluding Horns Rev offshore wind farm. This amounts to an installed capacity of just over $2200 \mathrm{MW}$. The demo-application runs using the ECMWF ensemble forecast system. Based on the global data assimilation, the calculations are initiated daily at 12:00 UTC and the calculation time is approximately 17 hours. 


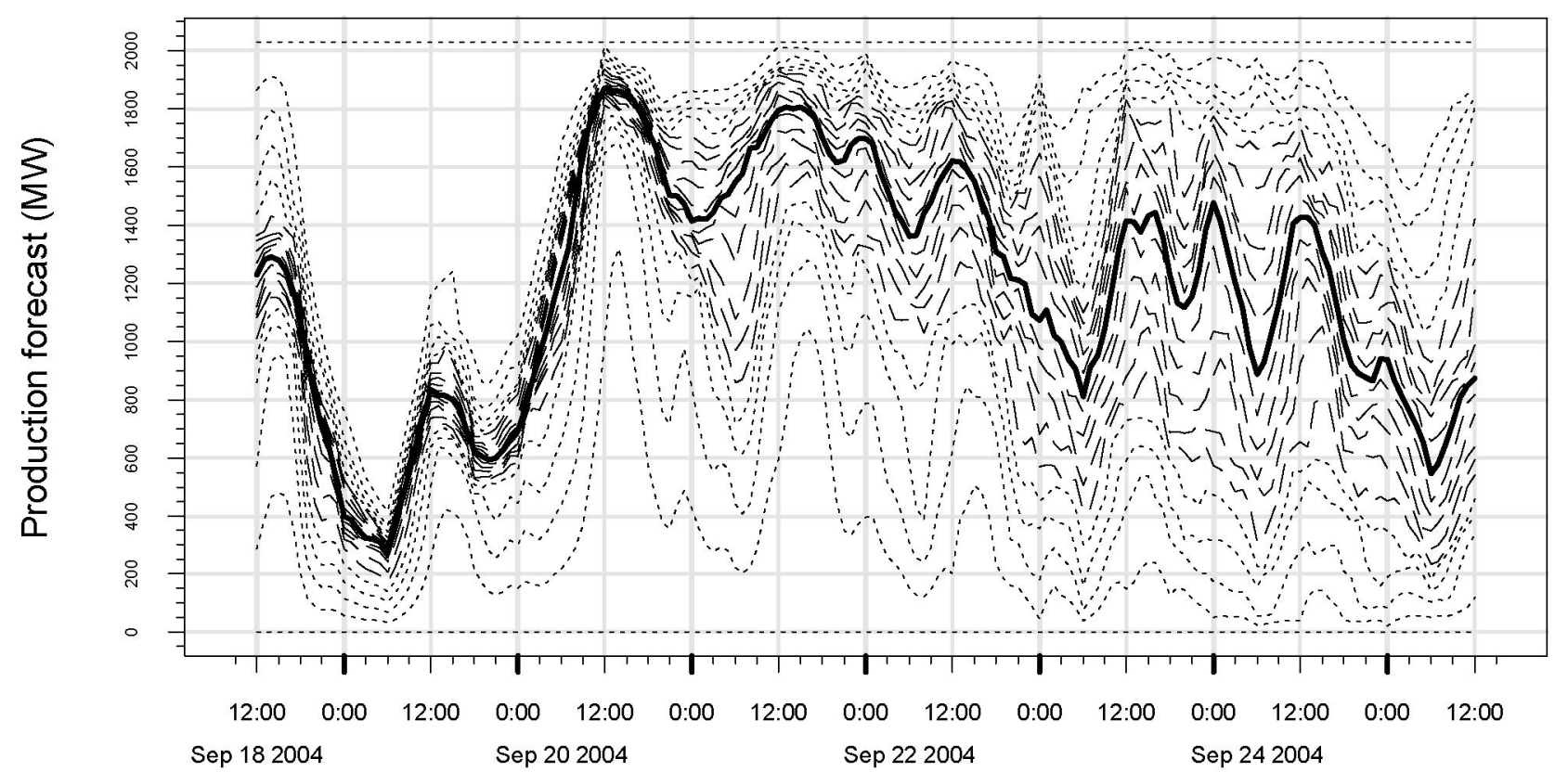

Fig. 1. Example of a quantile forecast of the wind power production in the Western part of Denmark, excluding Horns Rev (offshore). The forecast is based on the ECMWF ensemble forecast for which the calculations were initiated at Sept. 18, 2004, 12:00 (UTC). The forecast were ready for the plan submitted to the NordPool spot market on Sept. 19, 2004. Forecasted quantiles from $0 \%$ to $100 \%$ in steps of $5 \%$ are show. The $50 \%$ quantile is indicated by the bold line, quantiles from $25 \%$ to $75 \%$ by dashed lines, and the rest of the quantiles by dotted lines.

Forecasts are received for horizons up to 7 days, but due to the calculation time the effective horizon is closer to 6 days. The temporal resolution is six hours, the demo-application use linear interpolation between time points. See also [9], [10].

The demo-application has been used since November 2004. The general experience of the users is that it runs very stable. It is mainly used for planning related to horizons up to one week, e.g. unit commitment, fuel demand forecasts, in case of power station failure, and trading over the weekend on the German electricity exchange EEX [10, Sec. 5]. Furthermore, it supplements the operational forecast software WPPT [11], which focus on point forecasts for horizons up to approximately 40 hours, and is used for placing bids on the NordPool spot market.

Meteorological ensemble forecasting is a large and diverse field of science. Meteorological ensembles generated as described above are often termed initial value ensembles. Other types of meteorological ensemble forecasting systems exists in which different parametrizations of parts of the model is used. This amounts to use a number of meteorological models in parallel and differs from initial value ensembles by the fact that the performance of each of the individual models can be followed over time. See [12], [13] for an overview.

With respect to wind power forecasting a number of methods for producing quantile forecasts or similar information has previously been considered. These methods do not necessarily use meteorological ensembles. Quantile regression [14] is used in [15] and [16]. In [17]-[19] a quantity for measuring the agreement between consecutive forecasts is defined and this is used to predict the uncertainty of wind power forecasts. In [20] relations between typical weather situations and the magnitude of the forecast errors are identified. Parametric modelling of conditional variances and correlations is addressed in [21] and in [22] a full parametric multivariate time series model is developed.

The outline of the paper is as follows. In Sec. II the power curve model and a probability model are briefly described. Sec. III the results obtained from a trial period of 8 months is reported for the two setups of the demo-application described above. Finally, in Sec. IV we conclude on the paper.

\section{MODELS}

The models are empirical models identified by fitting the models to data consisting of actual power productions and forecasts of wind speed and direction. The forecasts used here are the so-called unperturbed forecasts which is one of the scenarios included in the ensemble forecast. The unperturbed forecast is a scenario generated using the same meteorological model as used in the ensemble forecasting system, but without perturbation of the initial values. The ECMWF ensemble forecasts are also perturbed randomly as the state evolves [3], this is however not implemented for the unperturbed forecast. The models used are described in [7], [8], here the models will be briefly described. For the data used in model development cut-out do not seem to occur [7].

\section{A. Power curve model}

The power curve model describes the relation between the forecasted wind conditions (speed and direction) and the wind power produced. Reasons for including the wind direction in 


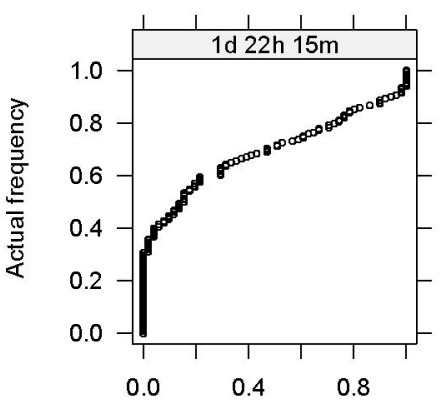

Nominal probability

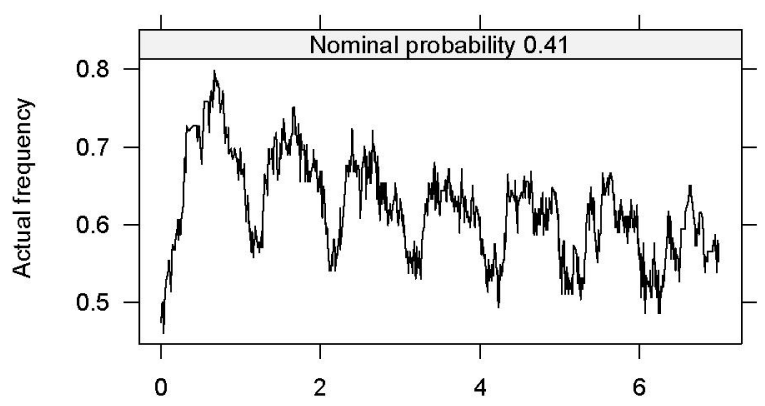

Horizon [days]

Fig. 2. Examples of the dependence of the actual observed frequencies on the nominal probability given a specific horizon (left) and on the horizon given a specific nominal probability (right). The example originates from [7], where data from a small offshore wind farm is used.

the model includes wake effects and direction dependent bias of the meteorological forecasts. The unperturbed forecast is of course associated with some uncertainty when compared to the wind speed and direction experienced by the wind farm, which in turn results in biased estimates [7], [23]-[25]. In order to preserve the probabilistic properties of the meteorological ensemble forecast when transforming the ensemble into power the estimation procedure should be unbiased. The estimation procedure described below aims at this, while at the same time using well tested methods.

To ensure that the full range of power productions are covered by the model the measured power outputs $P$ are transformed into the quantity $y$ using the relation

$$
y=c_{0}+c_{1} \log \frac{P-\underline{P}}{\bar{P}-P},
$$

where $c_{0}, c_{1}, \underline{P}$, and $\bar{P}$ are coefficients to be determined from data. The coefficients $\underline{P}$ and $\bar{P}$ are set just below and above the minimum and maximum observed power production of a sufficiently long period. This amounts to controlling these coefficients by the installed capacity. For details see [7]. The remaining coefficients which determine the placement and the slope of the transformation are found by nonlinear regression in the inverse of (1) when $y$ is replaced by the unperturbed forecast of the wind speed. This amounts to estimating a simple logistic-shaped power curve with a fixed span of power output.

To account for the wind direction, deviations from the logistic shape, and to adjust for bias originating from the uncertainty of the forecast the transformed power output is modelled as

$$
y=f(u, v)+g(u, v) \tau+e,
$$

where the wind velocity $(u, v)$ is a vector representation of the unperturbed forecast of speed and direction, $\tau$ is the forecast horizon of the meteorological model, $f$ and $g$ are smooth functions, and $e$ is the error term. The term $g(u, v) \tau$ adjust for an increasing uncertainty with horizon which may also depend on the wind speed and direction. In this way the bias of the estimate of $f(u, v)$ is reduced and after transformation to the original scale this is used as the power curve.
When no parametric assumptions are placed on the functions $f$ and $g$ the model (2) is a conditional parametric model [26], [27]. The functions are estimated by local regression with bandwidths chosen using the nearest neighbour principle and a tricube weight function. A local linear approximation is used for $f$ and a local constant approximation is used for $g$. More details can be found in [7].

\section{B. Probability model}

When the power curve model described in the previous section is used together with meteorological ensemble forecasts to produce wind power ensemble forecasts it is possible to check the probabilistic properties of the power ensemble forecasts. This requires nominal quantiles to be derived from the power ensemble forecasts for every horizon in every forecast, i.e. the ensemble forecast is transformed into a forecast of nominal quantiles. Hereafter the data must be grouped so that the actual frequencies can be compared with the corresponding numbers from the nominal quantiles.

Here it is chosen to group the data by horizon. Figure 2 show an example from [7]. In general this behavior is observed; i.e. a smooth dependence of the actual frequency on the nominal probability and a rather fluctuating dependence of the actual frequency on the horizon. See also [7], [8].

Due to the structure of the data a conditional parametric model [26], [27] is used where the dependence on the nominal probability $p_{n}$ is modelled as a cubic spline with boundary knots at 0 and 1 and two equidistantly placed internal knots [28]. The coefficients of the spline are estimated nonparametrically as smooth functions of the horizon $\tau$. The model is formally written

$$
\log \frac{p_{a}}{1-p_{a}}=\mathbf{B}\left(p_{n}\right) \boldsymbol{\theta}(\tau)+\epsilon
$$

where $p_{a}$ is the actual frequency, $\mathbf{B}\left(p_{n}\right)$ is a matrix representing a spline basis expansion of the nominal probability $p_{n}, \boldsymbol{\theta}(\tau)$ is the vector of smooth functions, and $\epsilon$ is the error. The logit-transformation of $p_{a}$ is used to ensure that the forecasted $p_{a}$ will be between 0 and 1. Estimation is performed using local regression with a fixed bandwidth and a tricube weight function. Due to the presence of peaks (Figure 2, right), 
the functions $\boldsymbol{\theta}(\tau)$ are locally approximated by 2 nd order polynomials. To avoid the problems in modelling the steep slopes corresponding to saturation for $p_{n}=0$ and $p_{n}=1$ the corresponding data is excluded before fitting the model to data. For details see [7].

\section{RESULTS FROM TRIAL PERIOD}

In this section the results from operation of the demoapplication described in the introduction are presented. The evaluation period is July 28, 2004 until March 31, 2005, i.e. a total of 8 months. According to plans the models were to be re-calibrated every month using data from the previous six months. Due to the status of the application the recalibration is not implemented as an automatic procedure and as a consequence re-calibration were not always performed on a regular basis. With the purpose of evaluating the original plans an off-line rerun were performed. In this paper we report the results of the rerun and briefly consideres one of the original runs in Sec. III-E. In [9] the results of the original run and the rerun is reported, together with the results of a rerun using ensemble forecasts from NCEP (National Centers for Environmental Prediction in the U.S.). See also [9] for details regarding how the meteorological ensembles are used.

When evaluating the performance of a quantile forecasting system it must be addressed to what extent the system is actually producing quantiles, e.g. it must be verified that in $75 \%$ of the cases the actual production is below the $75 \%$ quantile. This property is called the reliability of the system. Furthermore, the precision of the forecast must be addressed. Sharpness measures the average precision, e.g. the average of the distance between the $25 \%$ and the $75 \%$ quantile. Resolution measures the variation in precision, e.g. the standard deviation of the distance between the $25 \%$ and the $75 \%$ quantile. High resolution indicates that the system is able to differentiate between situations with low and high predictability. The concept originates from meteorology [29], but for models identified using data some part of the resolution will be artificial in the sense that it originates from random estimation error. Generally, this error has zero mean and therefore it will not influence sharpness in a systematic way.

When comparing several forecast systems these should only be compared w.r.t. sharpness and resolution if they are all reliable to some accepted degree. Other approaches to evaluation of ensemble forecasts has been suggested, see e.g. [30] and the references therein.

To further verify the appropriateness of the quantile forecasting system the spread / skill relationship is often considered. Here the relation between the magnitude of the observed forecast error of a point forecast and the uncertainty indicated by the quantile forecast system is analysed. The point forecast could be the forecast originating from the unperturbed scenario or it could be the $50 \%$ quantile forecast.

\section{A. Reliability}

In order to address the issue of reliability the forecasts are grouped by horizon in whole days and the actual frequencies

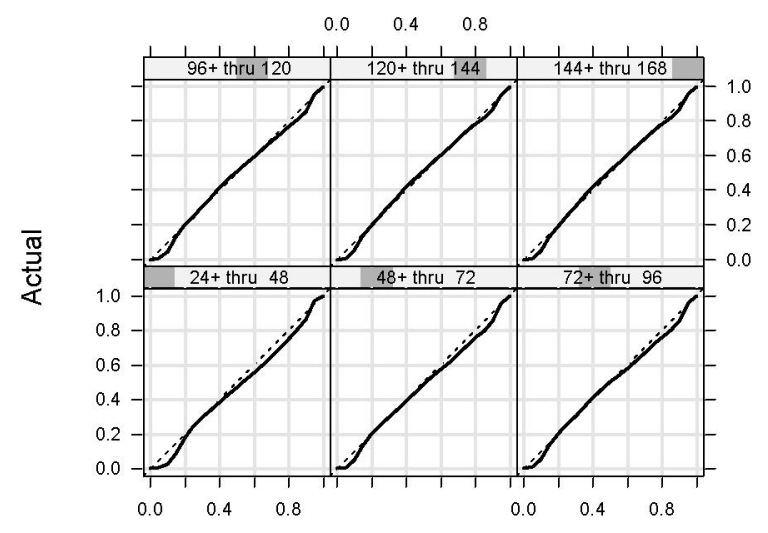

Nominal

Fig. 3. Nysted offshore wind farm: Actual frequencies versus nominal probabilities when grouping by horizon in hours as indicated on top of each plot.

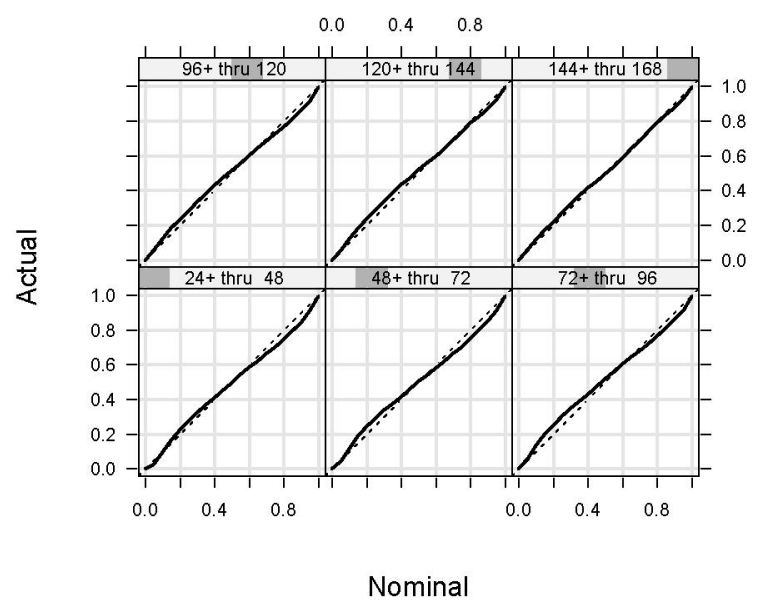

Fig. 4. Western Denmark: Actual frequencies versus nominal probabilities when grouping by horizon in hours as indicated on top of each plot.

by which the observed power production is below a given quantile is calculated for quantiles from $0 \%$ to $100 \%$ in steps of $5 \%$. A plot of the actual frequencies against the nominal probabilities is called a reliability diagram, which ideally coincide with the line of identity.

Based on these observed frequencies the reliability diagrams shown in Figures 3 and 4 are obtained. It is clear that the diagrams are close to the line of identity. Especially, for Western Denmark some curvature covering the whole plot range is observed. This may indicate that the number of knots used in the spline basis in (3) should be increased. Typically the deviation is in the order of two percent. For Nysted Offshore the reliability curve lies below the line of identity for both low and high nominal probabilities. The deviation is in the order of $5 \%$ for the extreme quantiles. For Western Denmark the reliability curve lies above the line of identity for low nominal probabilities, and below the line of identity for high nominal probabilities. In both cases the the deviation is up to $5 \%$.

Figures 5 and 6 show the corresponding reliability diagrams 


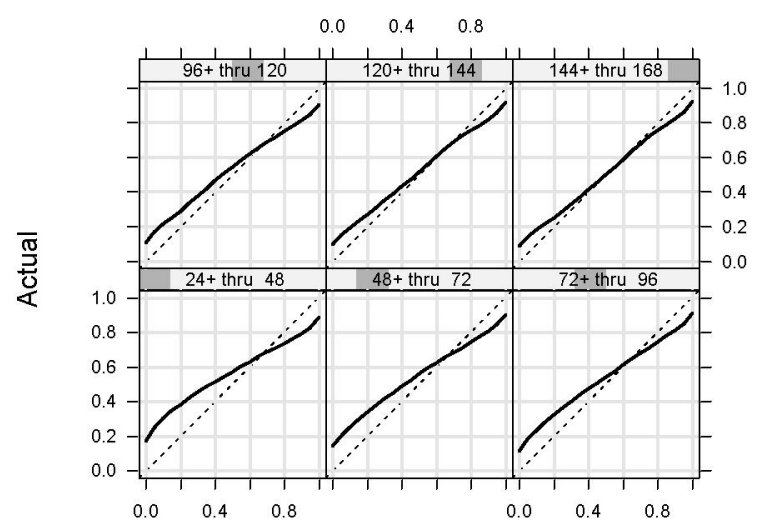

Nominal

Fig. 5. Nysted offshore wind farm: Actual frequencies versus nominal probabilities when not adjusting the quantiles using (3).

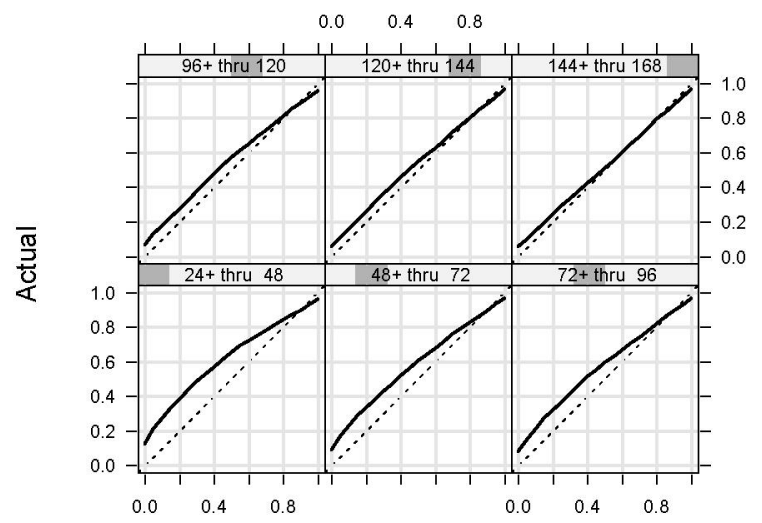

Nominal

Fig. 6. Western Denmark: Actual frequencies versus nominal probabilities when not adjusting the quantiles using (3).

when not using (3) to adjust the quantile forecasts. It is clear the the adjustment is important, especially for the shorter horizons. Note also that the adjustment required is different for Nysted offshore wind farm and for the regional forecast for Western Denmark. Furthermore, these plots show the saturation, e.g. for Nysted offshore wind farm for horizons between 24 and 48 hours quantiles below $20 \%$ and above $90 \%$ can not be reliably adjusted.

\section{B. Sharpness}

The sharpness of the quantile forecasts is depicted in Figure 7. Except for the short horizons, which are non-operational due to the calculation time, the plots show the expected behavior, i.e. the uncertainty increase with horizon and the relative uncertainty is larger for a wind farm than for a region. Furthermore, it is seen that the uncertainty is larger during the day than during the night; $0,1, \ldots, 7$ days corresponds to 12:00 UTC and Denmark is in the time zone UTC+1.

For Western Denmark the central $80 \%(90 \%-10 \%)$ is not larger than $60 \%$ of the installed capacity for any horizon. For 3 days the corresponding number is near $40 \%$. For Nysted

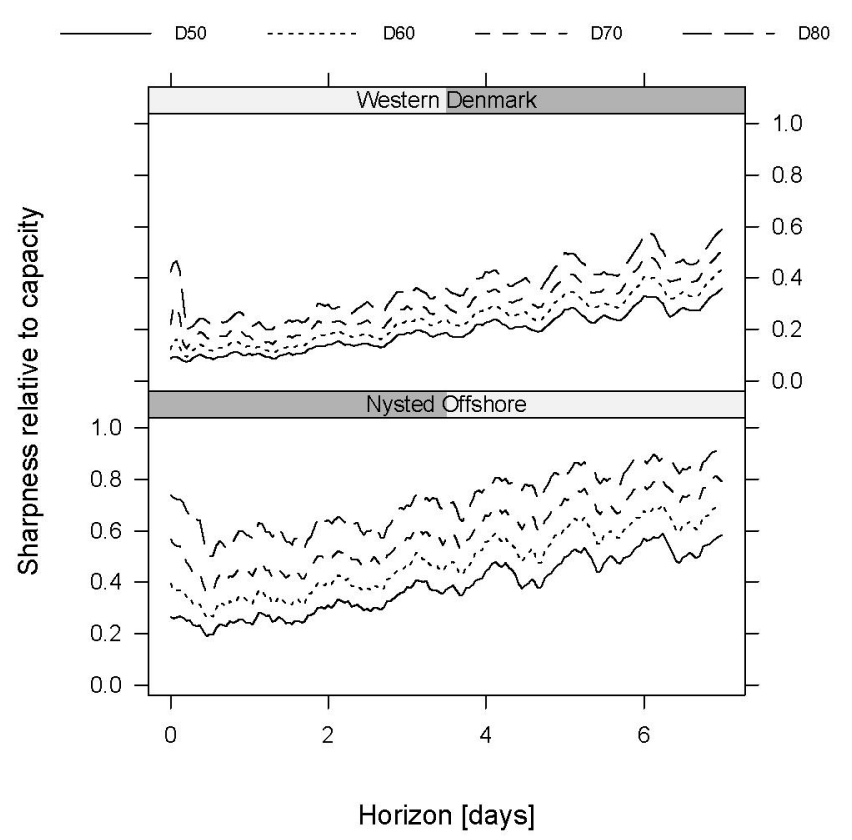

Fig. 7. Average difference between quantile forecasts symmetric about the $50 \%$ forecast; $75 \%-25 \%$ (D50), 80\%-20\% (D60), 85\%-15\% (D70), $90 \%-$ $10 \%$ (D80). The numbers are relative to installed capacity.

offshore wind farm the corresponding numbers are $90 \%$ and $70 \%$. The differences in predictive abilities for the two setups can also be quantified as the horizon for which the sharpness based on the central $50 \%$ reach $50 \%$ of installed capacity. For Nysted offshore wind farm this horizon is 4 days and for Western Denmark this horizon is not reached within 7 days.

\section{Resolution}

The resolution of the quantile forecasts is depicted in Figure 8. For Nysted offshore wind farm the resolution has a maximum around horizons of 2 days, i.e. for operational horizons around 1 day. Hereafter the resolution steadily declines indicating the increased uncertainty of the meteorological forecast and the limited production capacity of the wind farm. Note also that some of the curves cross. For Western Denmark the situation is different. The resolution as measured by the central $50 \%$ of the data (the bottom curve) is almost constant from 2 to 7 days. When using the central $80 \%$ only a minor decrease is observed.

\section{Spread/skill relationship}

For investigation of the spread / skill relationship the $50 \%$ quantile forecast is used as a point forecast. The magnitude of the error of this forecast is compared with the inter quartile range (IQR), i.e. the difference between the $75 \%$ and the $25 \%$ quantile forecast. If a spread / skill relationship in fact exists the spread of actual point forecast errors should increase with the IQR. Due to the size of plotting symbols this may not be visible on scatter-plots. For this reason we group the data by rounding the IQR relative to installed capacity to one decimal point. For each of these groups a range of quantiles of actual 


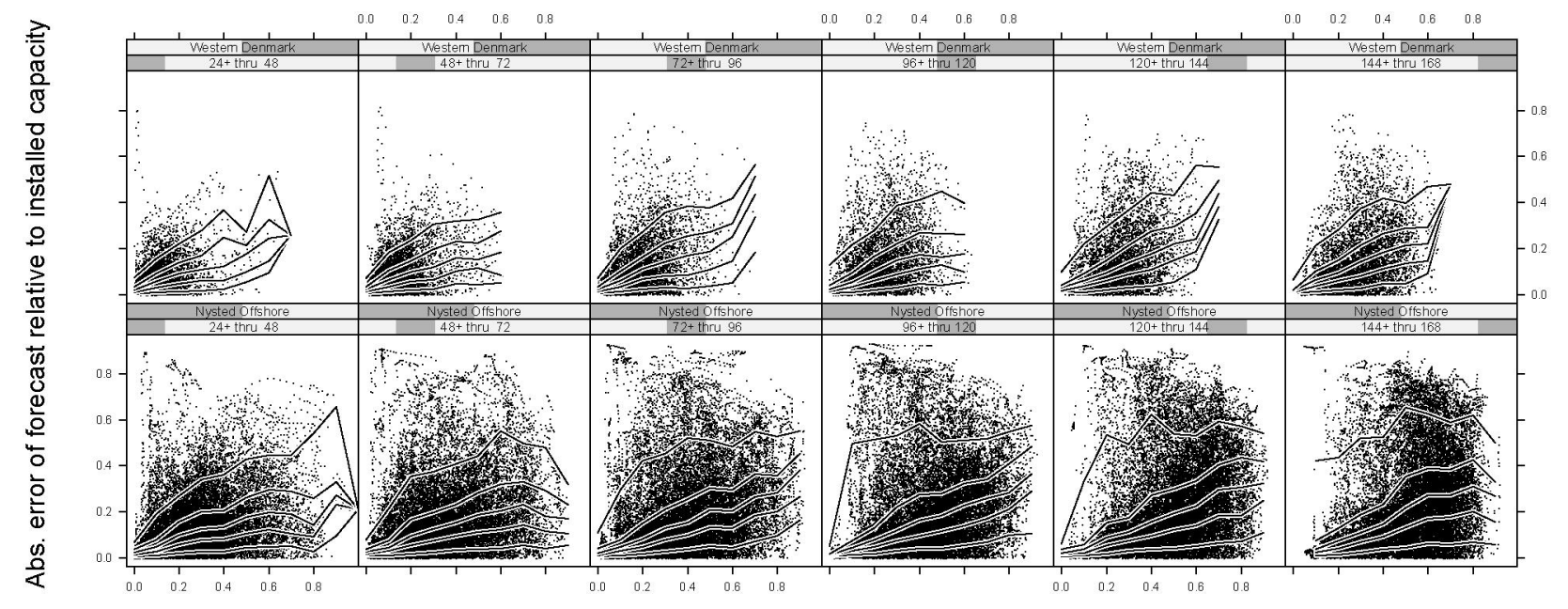

Inter quartile range relative to installed capacity

Fig. 9. Spread / skill relationship when the $50 \%$ quantile is used as the point forecast. The lines indicate the values for which $10 \%, 30 \%, 50 \%$, $70 \%$, and $90 \%$ of the absolute errors are below, when grouping by the value on the 1st axis rounded to one decimal point. The horizons in hours are indicated on top of each plot.

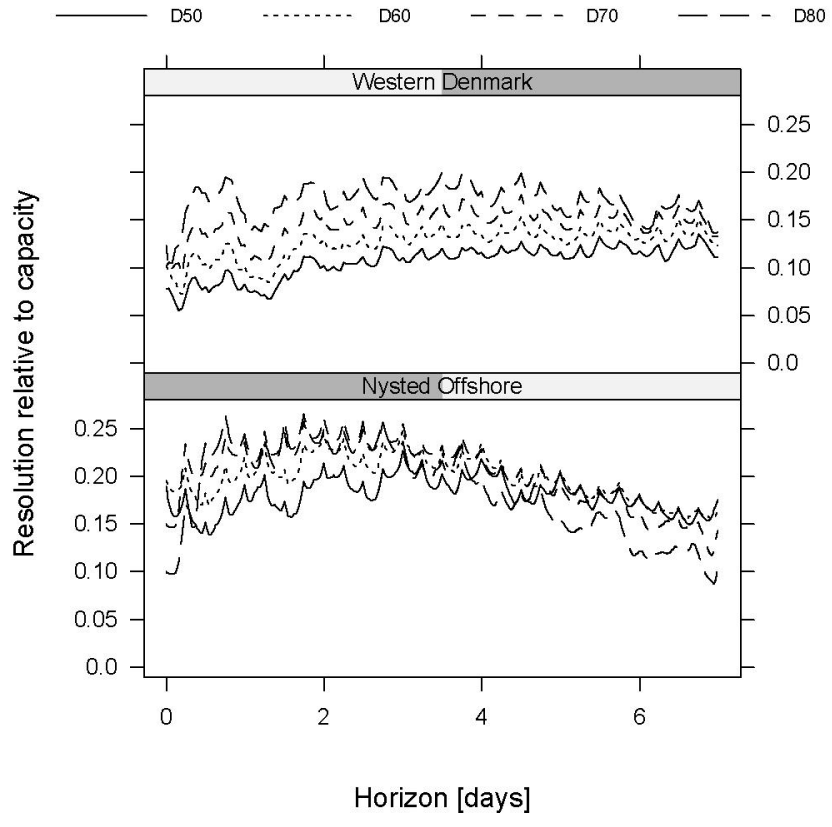

Fig. 8. Standard deviation of differences between quantile forecasts symmetric about the $50 \%$ forecast; $75 \%-25 \%$ (D50), $80 \%-20 \%$ (D60), $85 \%-15 \%$ (D70), $90 \%-10 \%$ (D80). The numbers are relative to installed capacity.

forecast errors are then computed. If spread / skill relationship exists these lines should increase with IQR.

The result is shown in Figure 9. First of all it is noted that the plots are very similar between horizons. This indicates that the horizon has been adequately adjusted for. For the regional forecasts (Western Denmark) values of IQR above 0.4 is rarely produced, especially for the shorter horizons. The overlayed lines, which are constructed as described above, clearly demonstrates the spread / skill relationship of the quantile forecast system. When the IQR is small the absolute error of the point forecast is also small; in fact most of the lines are near zero when IQR is zero. For instance, when the IQR is below $10 \%$ of installed capacity, the $50 \%$ line of absolute error is also below $10 \%$ of the installed capacity. Due to the limited number of points beyond the 5\% and $95 \%$ quantiles the $90 \%$ lines are somewhat fluctuating. Again, the difference between the regional forecasts (Western Denmark) and the wind farm (Nysted Offshore) is clearly visible on the plots, mainly because the regional forecasts results in smaller IQR. When only considering IQR where both setups have data $(\mathrm{IQR}<0.5)$ the slopes of the lines are similar.

\section{E. Regular calibration}

In order to demonstrate the importance of regular calibration the original original run of the setup for Western Denmark is considered in this section. This setup were only calibrated twice:

- A calibration using data up to May 31, 2004 was used for forecasting until February 3, 2005.

- A calibration using data up to December 31, 2004 was used for forecasting from February 4, 2005.

This was due to some difficulties within the chain of activities involved in the supply of power data to the re-calibration of the model.

The reliability diagrams of this original run are depicted in Figure 10. It is seen that the difference is often $10-20 \%$ and the results are not better than for the unadjusted quantile forecasts (Figure 6). Comparing with the results obtained using regular calibration (Figure 4) it is clear that regular calibration is indeed very important. 


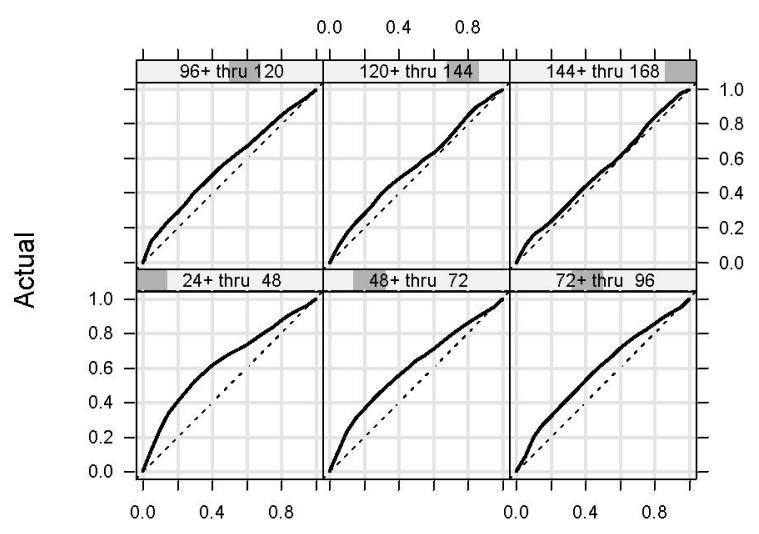

Nominal

Fig. 10. Western Denmark (original run): Actual frequencies versus nominal probabilities when grouping by horizon in hours as indicated on top of each plot.

\section{CONCLUSION}

The statistical models underlying a demo-application for producing quantile forecasts are described and the results from two actual actual applications of the demo-application have been analysed. In one setup the system is applied to a offshore wind farm (Nysted in Denmark) and in an other setup the system is applied as a regional forecasting tool (Western Denmark, except for Horns Rev).

It is shown that the system is able to produce probabilistic reliable forecasts usually with a difference of less than two percent between the nominal probabilities and actual frequencies. The precision of the forecasts is analysed in terms of sharpness and resolution. The analysis of sharpness show that for regional forecasts, even for 7 day horizons, the average size of the central $80 \%$ forecast intervals is not larger than $60 \%$ of the installed capacity. This indicates that even on these horizons the demo-application possess some predictive ability. For the wind farm the predictive ability is less pronounced on the long horizons. These findings are reflected in the resolution. A clear spread / skill relationship is demonstrated for both setups and the relationship does not depend on the horizon. This verifies that the quantile forecasts indeed contain relevant information regarding the uncertainty. Furthermore, some areas of further model improvements have been identified.

The estimation of the direction dependent power curve is achieved using observed power productions and meteorological forecasts. It is described how this procedure introduces bias in the estimation and which precautions can be taken to reduce this bias. However, the precautions are somewhat ad hoc based and in the future we hope to be able to develop methods which approach the issue of estimation bias in a more direct way. Given probabilistic reliable meteorological ensemble forecasts, the probability model would then be superfluous.

It has been shown that regular calibration is important and for a final software implementation the re-calibration should be performed automatically. The finding also confirms that the use of adaptive methods are important for wind power forecasting in general, see e.g. the analysis regarding the optimal forgetting factor in [31]. Possible explanations include, updates of the meteorological models, slowly varying effects not accounted for by the models, and changes in the population of wind turbines.

Finally, it should be noted that the precision by which the reliability diagrams are determined are not addressed in this paper. Methods based on $\chi^{2}$-tests have been suggested [15], but due to the inherent correlation of forecast errors this approach is problematic [30], [32]. In future research we hope to identify an appropriate set of solutions to such problems in wind energy forecasting.

\section{ACKNOWLEDGMENTS}

The results presented have been generated as part of the project Wind power prediction by ensemble forecasting sponsored by the Danish PSO fund (ORDRE-101295 / FU 2101), which is hereby greatly acknowledged. Furthermore, the authors wish to thank the European Centre for Medium-Range Weather Forecasts, and the National Centers for Environmental Prediction in the U.S. for supplying the data used in this study.

\section{REFERENCES}

[1] G. Giebel, J. Badger, L. Landberg, H. Nielsen, H. Madsen, K. Sattler, and H. Feddersen, "Wind power forecasting using ensembles," in Proceedings of the 2004 Global Windpower Conference and Exhibition, Chicago, Illinois, USA, March 2004, http://www.awea.org.

[2] F. Molteni, R. Buizza, T. Palmer, and T. Petroliagis, "The ECMWF ensemble prediction system: methodology and validation," Quart. J. Roy. Meteor: Soc., vol. 122, pp. 73-119, 1996.

[3] R. Buizza, M. Miller, and T. Palmer, "Stochastic representation of model uncertainties in the ECMWF Ensemble Prediction System," Quarterly Journal of the Royal Meteorological Society, vol. 125, no. 560, pp. 2887$2908,1999$.

[4] R. Buizza, "Trends in ensemble performance," ECMWF Newsletter, no. 94, pp. 2-5, 2002, http://www.ecmwf.int/publications/newsletters.

[5] Z. Toth and E. Kalnay, "Ensemble forecasting at NMC: The generation of perturbations," Bull. Amer: Meteor. Soc., vol. 74, pp. 1485-1490, 1993.

[6] - "Ensemble forecasting at NCEP and the breeding method," Monthly Weather Review, vol. 125, no. 12, pp. 3297-3319, 1997.

[7] H. A. Nielsen, H. Madsen, T. S. Nielsen, J. Badger, G. Giebel, L. Landberg, K. Sattler, and H. Feddersen, "Wind Power Ensemble Forecasting Using Wind Speed and Direction Ensembles from ECMWF or NCEP," Informatics and Mathematical Modelling, Tech. Rep., 2005, prepared under PSO-project FU2101, URL: http:/www.risoe.dk/zephyr/publ.htm.

[8] H. Nielsen, H. Madsen, T. Nielsen, J. Badger, G. Giebel, L. Landberg, K. Sattler, and H. Feddersen, "Wind power ensemble forecasting," in Proceedings of the 2004 Global Windpower Conference and Exhibition, Chicago, Illinois, USA, March 2004, http://www.awea.org.

[9] H. A. Nielsen, D. Yates, H. Madsen, T. S. Nielsen, J. Badger, G. Giebel, L. Landberg, K. Sattler, and H. Feddersen, "Analysis of the results of an on-line wind power quantile forecasting system," Informatics and Mathematical Modelling, Tech. Rep., 2005, prepared under PSO-project FU2101, URL: http://www.risoe.dk/zephyr/publ.htm.

[10] G. Giebel, J. Badger, L. Landberg, H. A. Nielsen, T. S. Nielsen, H. Madsen, K. Sattler, H. Feddersen, H. Vedel, J. Tøfting, L. Kruse, and L. Voulund, "Wind power prediction using ensembles," Ris $\varnothing$ National Laboratory, Tech. Rep. Risø-R-1527(EN), 2005, iSBN 87-550-3464-0.

[11] H. Madsen, H. A. Nielsen, and T. S. Nielsen, "A tool for predicting the wind power production of off-shore wind plants," in Proceedings of the Copenhagen Offshore Wind Conference \& Exhibition. Copenhagen: Danish Wind Industry Association, October 2005, http:/www. windpower.org/en/core.htm. 
[12] R. Buizza, P. L. Houtekamer, Z. Toth, G. Pellerin, M. Wei, and Y. Zhu, "Comparison of the ECMWF, MSC, and NCEP Global Ensemble Prediction Systems," Monthly Weather Review, vol. 133, pp. 1076-1097, 2005.

[13] H. Feddersen and K. Sattler, "Verification of wind forecasts for a set of experimental DMI-HIRLAM ensemble experiments," Danish Meteorological Institute, Scientific Report 05-01, 2005, http://www.dmi. $\mathrm{dk} / \mathrm{dmi} / \mathrm{sr} 05-01$

[14] R. Koenker, Quantile Regression. Cambridge University Press, 2005.

[15] J. B. Bremnes, "Probabilistic wind power forecasts using local quantile regression," Wind Energy, vol. 7, no. 1, pp. 47-54, 2004.

[16] H. A. Nielsen, H. Madsen, and T. S. Nielsen, "Using quantile regression to extend an existing wind power forecasting system with probabilistic forecasts," Wind Energy, 2006, accepted.

[17] P. Pinson and G. Kariniotakis, "On-line adaptation of confidence intervals based on weather stability for wind power forecasting," in Proceedings of the Global Wind Energy Conference \& Exhibition, Chicago, Illinois, USA, 2004, http://www.awea.org.

[18] — " "On-line assessment of prediction risk for wind power production forecasts," Wind Energy, vol. 7, no. 2, pp. 119-132, 2004.

[19] _ , "On-line assessment of prediction risk for wind power production forecasts," in Proceedings of the European Wind Energy Conference \& Exhibition, Madrid, Spain, 2003, http://www.ewea.org.

[20] M. Lange and D. Heinemann, "Relating the uncertainty of short-term wind speed predictions to meteorological situations with methods from synoptic climatology," in Proceedings of the European Wind Energy Conference \& Exhibition, Madrid, Spain, 2003, http://www.ewea.org.

[21] J. B. Bremnes, "Probabilistic wind power forecasts by means of statistical model," in Proceedings of the IEA R\&D Wind Annex XI Joint Action Symposium on Wind Forecasting Techniques, Norrköping, Sweden, December 3-4 2002, pp. 103-114.

[22] H. A. Nielsen and H. Madsen, "Analyse og simulering af prædiktionsfejl for vindenergiproduktion ved indmelding til NordPool," Informatik og Matematisk Modellering, Danmarks Tekniske Universitet, Lyngby, Tech. Rep., 2002, i samarbejde med Eltra a.m.b.a.

[23] H. A. Nielsen, T. S. Nielsen, and H. Madsen, "On on-line systems for short-term forecasting for energy systems," in Proceedings of the $O R$ 2002 conference. Klagenfurt, Austria: Springer, 2002, pp. 265-271.

[24] - "Using meteorological forecasts for short term wind power forecasting," in Proceedings of the IEA R\&D Wind Annex XI Joint ACtion Symposium on Wind Forecasting Techniques, Norrköping, Sweden, December 3-4 2002, pp. 49-58.

[25] B. Jonsson, "Prediction with a linear regression model and errors in a regressor," International Journal of Forecasting, vol. 10, no. 4, pp. $549-555,1994$.

[26] W. Cleveland, Multivariate Analysis and Its Applications. Hayward: Institute of Mathematical Statistics, 1994, ch. Coplots, Nonparametric Regression, and conditionally Parametric Fits, pp. 21-36.

[27] T. Hastie and R. Tibshirani, "Varying-coefficient models," Journal of the Royal Statistical Society, Series B, Methodological, vol. 55, pp. 757-796, 1993.

[28] C. de Boor, A Practical Guide to Splines. Berlin: Springer Verlag, 1978.

[29] I. T. Jolliffe and D. B. Stephenson, Eds., Forecast verification - a practitioner's guide in atmospheric science. Wiley, 2003.

[30] P. Pinson, G. Kariniotakis, H. A. Nielsen, T. S. Nielsen, and H. Madsen, "Properties of quantile and interval forecasts of wind generation and their evaluation," in Proceedings of the European Wind Energy Conference \& Exhibition. Athens: EWEA, March 2006, http://www.ewea.org, to appear.

[31] T. Nielsen, Ed., Using Meteorological Forecasts in On-line Predictions of Wind Power. Eltra, DK-7000 Fredericia, Denmark, 1999, iSBN: 87-90707-18-4.

[32] T. M. Hamill, "Interpretation of rank histograms for verifying ensemble forecasts," Monthly Weather Review, vol. 129, no. 3, pp. 550-560, 2001. 